\title{
Food Marketing in an Obesogenic Environment: a Narrative Overview of the Potential of Healthy Food Promotion to Children and Adults
}

\author{
Frans Folkvord ${ }^{1,2}$ (D) Roel C. J. Hermans ${ }^{3,4}$ (D) \\ Accepted: 29 September 2020 / Published online: 10 October 2020 \\ (C) The Author(s) 2020
}

\begin{abstract}
Purpose of Review There is abundant evidence that food marketing influences children's and adults' food preferences and consumption. As such, exposure to unhealthy food marketing is a widely acknowledged risk factor contributing to the development of overweight and obesity. Less is known about the effects of healthy food promotion on people's dietary behavior. This narrative review describes research from the past 5 years focused on the effects of healthy food marketing on children's and adults' food preferences and dietary intake. Our aim is to gain insight into the potential effects and mechanistic underpinnings of healthy food promotion, thereby building on existing knowledge on underlying mechanisms of the effectiveness of unhealthy food marketing.

Recent Findings Only a small number of studies directly examined the effects of healthy food promotion on children's and adults' dietary behavior. Most studies targeted children's fruit and/or vegetable intake and used a variety of marketing techniques, ranging from television adverts to social media influencer marketing. Six out of ten studies found a positive effect of healthy food promotion, indicating that healthy food marketing has the potential to influence dietary behavior.

Summary Food marketing is highly effective in stimulating and reinforcing food consumption, in particular for energy-dense foods. Further investigation and experimentation into the efficiency and effectiveness of healthy food promotion are needed to determine how marketing techniques could be used to improve dietary behavior. The healthy food promotion model provides a framework for future research in this area.
\end{abstract}

Keywords Food marketing $\cdot$ Overweight $\cdot$ Chronic diseases $\cdot$ Healthy food promotion

\section{Introduction}

During the last decades, our food environment has evolved in such a way that it is simple to get access to inexpensive and

This article is part of the Topical Collection on Food Addiction

Frans Folkvord

fransfolkvord@gmail.com

Roel C. J. Hermans

r.hermans@maastrichtuniversity.nl

1 Tilburg School of Humanities and Digital Sciences, Communication and Information Science, Tilburg University,

Tilburg, The Netherlands

2 Open Evidence Research, Barcelona, Spain

3 Department of Health Promotion, NUTRIM School of Nutrition and Translational Research in Metabolism, Maastricht University, Maastricht, The Netherlands

4 The Netherlands Nutrition Centre, The Hague, The Netherlands palatable food, often referred to as an obesogenic food environment $[1 \bullet \cdot]$. High accessibility to energy-dense foods and repeated exposure to food cues, such as the sight and smell of food, stimulate individuals to consume more energy than required $[2,3]$. With this in mind, experts have concluded that the global rise in overweight and diet-related noncommunicable diseases is the result of a food and beverage environment that perpetuates poor dietary behaviors. As such, they proposed that major improvements in the current food environment are needed if the global targets of halting the rise in obesity are to be met $[4,5]$.

One aspect of the food environment that is known to exert a powerful influence on children and (young) adults' eating patterns is food marketing [6-10]. In this article, food marketing is used to describe any form of commercial advertising that is designed to increase the recognition, appeal, and/or consumption of particular food products, brands, and services [11]. Within this context, food advertising provides the essential link between the products produced and the creation of demand for these products. To date, food advertising almost 
exclusively promotes ultra-processed food and beverage products high in fats (i.e., saturated and trans fats), free sugars, and sodium associated with poor diet quality [12]. There is abundant evidence that this type of advertising not only affects consumers' preferences and purchasing behavior but also increases the consumption of marketed foods [9, 13-16].

In the past years, countries have globally enacted policies designed to promote responsible marketing, from national legislations related to the restriction of food advertising during children's television viewing times to policies on food and beverage marketing in schools [17, 18]. Despite this, marketing for low-nutrition, energy-dense foods and drinks continues to be highly salient features of the current food environment. In light of the current obesogenic food environment, it is therefore essential to modify towards a "healthygenic" food environment in which strategies that promote availability, accessibility, and affordability of foods and food groups that provide required nutrients, prevent chronic diseases, and promote overall health are implemented across the food system $[1 \bullet \bullet$. As part of this, new and innovative methods are needed to increase attention towards these foods and food groups that reinforce its value to children and (young) adults. In line with the promotion of healthy food model [19*•], it is proposed that healthy food promotion may be a mean to do so.

This narrative review aims to gain insight into the potential effects and mechanistic underpinnings of healthy food promotion, thereby building on existing knowledge on underlying mechanisms of effective unhealthy food marketing. To achieve this, we first discuss the three foundational assumptions that aim to explain the mechanisms behind unhealthy food marketing using the reactivity to embedded food cues in advertising model (REFCAM). After this, we describe research from the past 5 years focused on the effects of healthy food promotion on children's and adults' dietary behavior, present the five foundational assumptions of the healthy food promotion model, and describe salient research gaps that need to be filled to determine how marketing techniques could be used to improve dietary behavior.

\section{The Underlying Mechanism of Unhealthy Food Marketing}

One recently developed theoretical model that describes the underlying mechanism of unhealthy food marketing is the REFCAM (see [6]). The REFCAM integrates, among other theoretical frameworks, the processing of commercialized media content model [20] and the differential susceptibility to media effects model [21] and is built on three main assumptions. First, the model assumes a 2-step process of the advertising itself, where (a) food cues induce physiological and psychological reactivity to energy-dense foods (labeled as the advertising effect process), which (b) leads to a reciprocal relationship with eating behavior (labeled as the incentivesensitization process). Conditioned stimuli, such as the food cues in advertising, activate a central appetitive state, resulting in eating behavior responses. This reaction to food cues develops in becoming a stronger predictor of subsequent food intake, which consequently leads to an increased food intake that reinforces the reactivity to food cues, resulting in a reciprocal relation between food cue reactivity and food intake, identified as the incentive-sensitization process. Several studies have supported these assumed processes (1) that food cues of energy-dense snacks induce salivary responses [22], heightened brain responses related to food intake [23], dwell time and pupil dilation [24], and increased attention [25, 26], and that (2) this effect is stronger for individuals with overweight or obesity [26-28].

The second assumption is that message factors, such as the level of integration of food cues, moderate their effect, because the message and its media context influence the level of elaboration and reduce skepticism towards the food advertising [20]. Food advertising increasingly is integrated in the entertaining content of media messages (e.g., advergames, social media advertising, product placement), thereby reducing the possibility to activate cognitive skepticism and increasing the effect of the food advertisement.

The third assumption is that individual dispositional factors determine susceptibility to food cues in advertisements [21]. Evidence clearly shows that food advertising affects eating behavior [6], but stronger effects have been found for individuals with a higher weight status [29], more impulsive individuals [30, 31], restrained eaters [32], or children who are prohibited to consume candies [33॰]. The REFCAM has shown to be adequate to describe, understand, and predict the effects of food cues in advertising on the intake of palatable snacks [6].

\section{A Narrative Overview of the Potential of Healthy Food Promotion}

In line with the REFCAM [6], it is highly promising to examine whether, how, and when healthy food promotion may help to improve the intake of foods or food groups that provide required nutrients, prevent chronic diseases, and promote overall health, such as fruit or vegetables. Although this specific type of food promotion may be intuitively appealing, not much is known about the efficiency and effectiveness of healthy food promotion on children and adults' dietary behavior. Our first aim, therefore, is to explore whether there is recent empirical evidence $(<5$ years) supporting the proposition that healthy food promotion may help to encourage healthy eating patterns among children and adults. The second aim is to explore which marketing techniques are used in this domain. To reach these objectives, we provide a narrative 
review of experimental studies that examine differences in dietary behavior between an experimental group exposed to healthy food promotion and a control group exposed to unhealthy food or non-food-related promotion content.

Of the ten studies that were found, four studies focused on studying vegetable consumption (i.e., attitude, intention, or behavior) [34-37], two studies on fruit consumption [38, $39]$, two on fruit and vegetable consumption [40, 41], and two studies focused on meal selection and food preferences including healthy choices (e.g., water, carrot sticks, strawberries, or a fruit bag) $[13,42]$. The marketing techniques that were used in these studies were social media influencer marketing [35, 37, 40], advergames [36, 39], promotional characters $[34,38,42]$, product placement [38], and television adverts [13]. Eight out of ten studies focused on children [13, 34, $36,38-42]$, one study included adults [37] and one study included adolescents [35]. All studies included participants of both sexes, with an almost equal number of both males and females in almost all studies. Studies were conducted in The Netherlands $(n=4)$, UK $(n=2)$, France $(n=1)$, Portugal $(n=1)$, Italy $(n=1)$, and Mexico $(n=1)$.

Evidence in support of the proposition that healthy food promotion may help to encourage healthy eating patterns among children and adults was found in six out of ten studies. These studies demonstrated a positive effect of healthy food promotion on product attitude and purchase intention [36-38], food preference, choice and selection [38, 41, 42], or actual food consumption [34, 35, 37, 42].

\section{The Healthy Food Promotion Model}

In line with the REFCAM, the healthy food promotion model is aimed to gain insight into the underlying mechanism of healthy food promotion. When we talk about food promotion in this theoretical framework, we will discuss the same marketing techniques that are used for the promotion of unhealthy foods. The model contains five foundational assumptions (see Fig. 1): (1) through food promotion, we will increase the attention towards the value of healthy foods (e.g., liking and wanting), and as a result, it will become more reinforcing, leading to (2) a reciprocal relation to dietary intake. In time, this will (3) lead to increased intake of healthy foods and as such will lead to habit formation with regard to the intake of the specific food or food groups. Once this habit is increased in influence and people eat healthier foods more often for longer periods of time, it will lead (4) to improved health states as indicated by physiological (e.g., blood lipids, insulin sensitivity, blood pressure, neurological activity, inflammation levels, weight) and psychological (e.g., craving, hunger, mental well-being) improvements. Finally, as the differential susceptibility to media effects model [21] has shown, (5) individual and societal factors (e.g., body mass index, gender, impulsivity, socioeconomic status, parental feeding style, food fussiness) importantly determine susceptibility to healthy food promotion.

\section{Future Research Directions}

Firstly, because food marketing research has mainly been focusing on the effects of unhealthy food marketing [6] and only a small number of studies have focused on healthy food promotion, further investigation and experimentation into the efficiency and effectiveness of healthy food promotion are needed to determine how marketing techniques could be used to improve dietary behavior. One research direction that has not been studied at all is whether healthy food promotion influences craving or other physiological and psychological responses that prepare people for future intake. One of the effects of unhealthy food marketing is that it leads to increased saliva secretion and the uptake of appetite-related hormones such ghrelin and insulin [6]. Furthermore, it has been shown that food marketing for unhealthy foods affects thoughts and

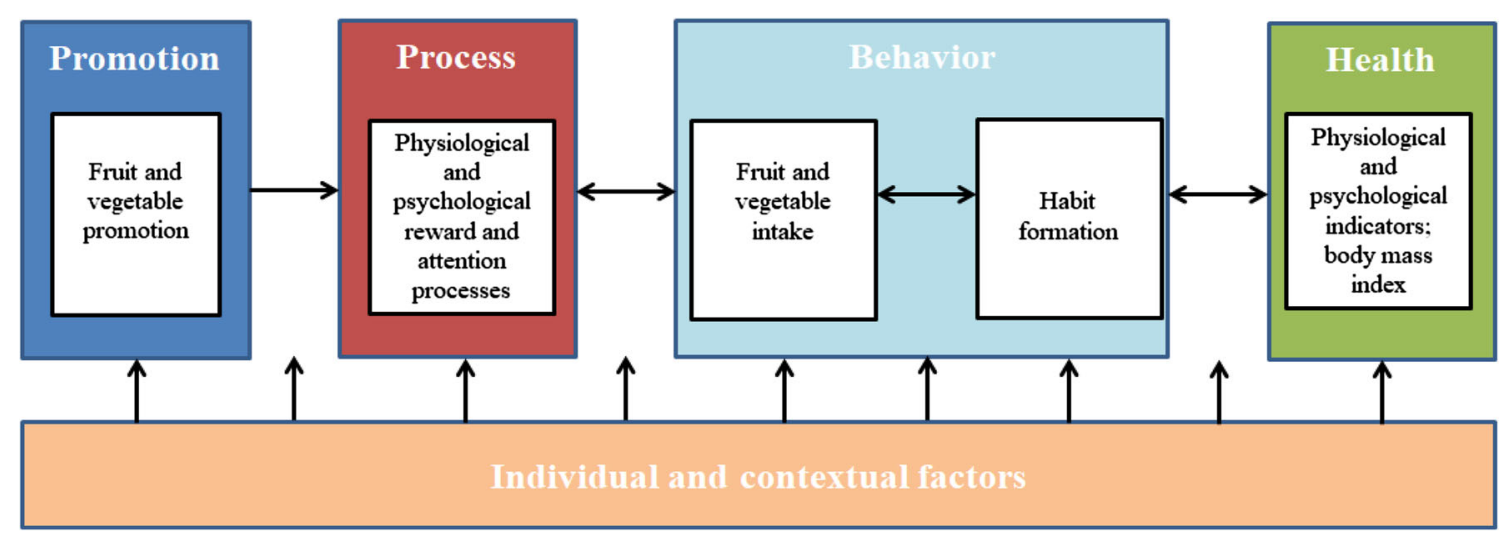

Fig. 1 The healthy food promotion model, adapted version from Folkvord [19••]. The single arrows pointing at the concepts indicate that we expect a direct effect on these concepts. The single arrows pointing at the arrows indicate that they moderate this suggested effect. The double arrows indicate a reciprocal relation between the concepts 
motivations related to food intake [19••]. To date, it is unknown whether the same processes are induced when people are exposed to healthy food promotion. Research examining this effect in healthy food promotion is scarce, although the first result is promising. In line with this, as exposure to food marketing is omnipresent and starts at a young age, future research could examine if extended and prolonged exposure to healthy food promotion may help to increase the rewarding value of healthy foods or food groups. The healthy food promotion model considers the effect of food promotion techniques on food intake (via cue reactivity) as a process of classical and operant conditioning, assuming that the same mechanism may be applicable to healthy food marketing. Until now, however, it is unclear whether this is indeed the case, and therefore, this should be tested in future work.

Secondly, almost no empirical studies have focused on potential individual and contextual factors influencing the relationship between healthy food promotion and dietary behavior. Following the differential susceptibility to media effects model [21], it is important to establish these individual and contextual factors in order to better understand the variability in the processing of healthy food promotion, the attention for and reinforcing value of these foods, and subsequent intake. An increased understanding of potential differential susceptibility to healthy food promotion is assumed to lead to more effective intervention strategies for different products.

\section{Conclusions}

To date, there is ample evidence that unhealthy food marketing has direct and adverse effects on children's and (young) adults' food preferences and consumption. As a result, it is an acknowledged risk factor contributing to the development of overweight and obesity.

In addition to existing strategies that help to improve people's dietary behavior, new and innovative methods are needed to reinforce the value of healthy foods and food groups [43].

The main aim of this narrative review was to gain insight into the potential effects and mechanistic underpinnings of healthy food promotion, thereby building on existing knowledge on underlying mechanisms of effective unhealthy food marketing. As part of this, we discussed research from the past 5 years focused on the effects of healthy food promotion on children's and adults' dietary behavior and describe salient research gaps that need to be filled to determine how marketing techniques could be used to improve dietary behavior. The novelty of this article is that it provides a clear insight into both the mechanistic underpinnings of unhealthy food advertising and the promotion of healthier foods [19*0]. Our healthy food promotion model provides a framework that integrates existing empirical evidence on how food promotion techniques affect eating behavior and provides the reader with future research questions. We believe that the healthy food promotion model has the potential to provide society, policymakers, and scholars from a great variety of scientific disciplines with guidance to effectively improve the promotion of healthier foods among different target groups. Most recently, scholars from all over the world have been examining tools and methodologies to improve dietary intake among people to improve health and well-being. The theoretical model presented in this study can enhance and reinforce these methods.

The theoretical and political philosophy concept of libertarian paternalism [44], stating that it is possible to affect behavior in a positive way in order to make people healthier or happier, respecting people's freedom of choice and autonomy but directing them indirectly towards a better decision, has gained interest and popularity the last few decades. Exploiting human's decision errors and cognitive biases to motivate people to buy unhealthy food products can also be used to reverse the trend of obesity and promote healthier foods. In times of increasing obesity rates and related rises in health service utilization and costs, a public debate on advertising techniques that attempt to persuade people seems timely. Execution of healthy food promotion activities will require bold action by policymakers to increase the promotion of healthier foods and as a consequence increase people's health and well-being on the long term.

Authors' Contributions FF and RCJH were both involved in the conception and design of this article. FF and RCJH performed the literature search and analyzed the data. FF drafted the first concepts of the paper, which were critically revised and complemented by RCJH.

Funding This work was funded by Tilburg School of Humanities and Digital Sciences, Communication and Information Science, Tilburg University, the Netherlands.

\section{Compliance with Ethical Standards}

The current study is compliant with ethical standards.

Conflict of Interest The authors declare that they have no conflict of interest.

Open Access This article is licensed under a Creative Commons Attribution 4.0 International License, which permits use, sharing, adaptation, distribution and reproduction in any medium or format, as long as you give appropriate credit to the original author(s) and the source, provide a link to the Creative Commons licence, and indicate if changes were made. The images or other third party material in this article are included in the article's Creative Commons licence, unless indicated otherwise in a credit line to the material. If material is not included in the article's Creative Commons licence and your intended use is not permitted by statutory regulation or exceeds the permitted use, you will need to obtain permission directly from the copyright holder. To view a copy of this licence, visit http://creativecommons.org/licenses/by/4.0/. 


\section{References}

Papers of particular interest, published recently, have been highlighted as:

- Of importance

•- Of major importance

1.• Swinburn BA, Kraak VI, Allender S, Atkins VJ, Baker PI, Bogard JR, et al. The global syndemic of obesity, undernutrition, and climate change: the Lancet Commission report. Lancet. 2019;393(10173):791-846 This is a very important paper because it shows the impact of the food system we currently have, calling for a necessary change from the obesogenic environment we currently have to the healthogenic the authors, and we, propose.

2. Boswell RG, Kober H. Food cue reactivity and craving predict eating and weight gain: a meta-analytic review. Obes Rev. 2016;17(2):159-77.

3. Steeves EA, Martins PA, Gittelsohn J. Changing the food environment for obesity prevention: key gaps and future directions. Curr Obes Rep. 2014;3(4):451-8.

4. Swinburn BA, Sacks G, Hall KD, McPherson K, Finegood DT, Moodie ML, et al. The global obesity pandemic: shaped by global drivers and local environments. Lancet. 2011;378(9793):804-14.

5. Swinburn B, Kraak V, Rutter H, Vandevijvere S, Lobstein T, Sacks $\mathrm{G}$, et al. Strengthening of accountability systems to create healthy food environments and reduce global obesity. Lancet. 2015;385(9986):2534-45.

6. Folkvord F, Anschütz DJ, Boyland E, Kelly B, Buijzen M. Food advertising and eating behavior in children. Curr Opin Behav Sci. 2016;9:26-31.

7. Larson NI, Story MT, Nelson MC. Neighborhood environments: disparities in access to healthy foods in the US. Am J Prev Med. 2009;36(1):74-81.

8. Harris JL, Bargh JA, Brownell KD. Priming effects of television food advertising on eating behavior. Health Psychol. 2009;28(4): 404-13.

9. Smith R, Kelly B, Yeatman H, Boyland E. Food marketing influences children's attitudes, preferences and consumption: a systematic critical review. Nutrients. 2019;11(4):875

10. Harris JL, Fleming-Milici F. Food marketing to adolescents and young adults. Psychol Food Mark Overeating. 2019;31:25.

11. Cairns G, Angus K, Hastings G, Caraher M. Systematic reviews of the evidence on the nature, extent and effects of food marketing to children. A retrospective summary. Appetite. 2013;62:209-15.

12. Kraak VI, Rincón-Gallardo Patiño S, Sacks G. An accountability evaluation for the International Food \& Beverage Alliance's global policy on marketing communications to children to reduce obesity: a narrative review to inform policy. Obes Rev. 2019;20:90-106.

13. Boyland EJ, Whalen R. Food advertising to children and its effects on diet: review of recent prevalence and impact data. Pediatr Diabetes. 2015;16(5):331-7.

14. Qutteina Y, De Backer C, Smits T. Media food marketing and eating outcomes among pre-adolescents and adolescents: a systematic review and meta-analysis. Obes Rev. 2019;20(12):1708-19.

15. Hallez L, Qutteina Y, Raedschelders M, Boen F, Smits T. That's my cue to eat: a systematic review of the persuasiveness of front-ofpack cues on food packages for children vs. adults. Nutrients. 2020;12(4): 1062.

16. Russell SJ, Croker H, Viner RM. The effect of screen advertising on children's dietary intake: a systematic review and meta-analysis. Obes Rev. 2019 Apr;20(4):554-68.

17. World Health Organization. Set of recommendations in the marketing of foods and non-alcoholic beverages to children. 2010.
18.• World Health Organization. Evaluating implementation of the WHO set of recommendations on the marketing of foods and non-alcoholic beverages to children. Progress, challenges and guidance for next steps in the WHO European Region. 2018. This is an important report because it clearly shows that there remains an overwhelming preference for self-regulation by the food and advertising industry that has been shown to be ineffective.

19.• Folkvord F, editor. The psychology of food marketing and overeating. Routledge; 2019. This book shows clearly how food marketing influences different age groups and what the consequences are. In addition, it provides insights into how the same techniques could be used to create a healthier food environment by using the healthy food promotion theoretical model.

20. Buijzen M, Van Reijmersdal EA, Owen LH. Introducing the PCMC model: an investigative framework for young people's processing of commercialized media content. Commun Theory. 2010;20(4):427-50.

21. Valkenburg PM, Peter J. The differential susceptibility to media effects model. J Commun. 2013;63(2):221-43.

22. Keesman M, Aarts H, Vermeent S, Häfner M, Papies EK. Consumption simulations induce salivation to food cues. PLoS One. 2016;11(11):e0165449.

23. Masterson TD, Bermudez MA, Austen M, Lundquist E, Pearce AL, Bruce AS, et al. Food commercials do not affect energy intake in a laboratory meal but do alter brain responses to visual food cues in children. Appetite. 2019;132:154-65.

24. Folkvord F, van't Riet J. The persuasive effect of advergames promoting unhealthy foods among children: a meta-analysis. Appetite. 2018;129:245-51

25. Spielvogel I, Matthes J, Naderer B, Karsay K. A treat for the eyes. An eye-tracking study on children's attention to unhealthy and healthy food cues in media content. Appetite. 2018;125:63-71 This is a relevant study because it shows differences in attention among children for unhealthy and healthy food cues, which is an important explanation for the differences in food intake.

26. Folkvord F, Anschütz DJ, Buijzen M. Attentional bias for food cues in advertising among overweight and hungry children: an explorative experimental study. Food Qual Prefer. 2020;79:103792.

27. Folkvord F, Anschütz DJ, Wiers RW, Buijzen M. The role of attentional bias in the effect of food advertising on actual food intake among children. Appetite. 2015;84:251-8.

28. Deluchi M, Costa FS, Friedman R, Gonçalves R, Bizarro L. Attentional bias to unhealthy food in individuals with severe obesity and binge eating. Appetite. 2017;108:471-6.

29. Norman J, Kelly B, McMahon AT, Boyland E, Baur LA, Chapman $\mathrm{K}$, et al. Sustained impact of energy-dense TV and online food advertising on children's dietary intake: a within-subject, randomised, crossover, counter-balanced trial. Int J Behav Nutr Phys Act. 2018;15(1):37.

30. Hershko S, Cortese S, Ert E, Aronis A, Maeir A, Pollak Y. Advertising influences food choices of university students with ADHD. J Atten Disord. 2019;1087054719886353.

31. Folkvord F, Veling H, Hoeken H. Targeting implicit approach reactions to snack food in children: effects on intake. Health Psychol. 2016;35(8):919-22.

32. Alblas MC, Mollen S, Fransen ML, van den Putte B. Food at first sight: visual attention to palatable food cues on TV and subsequent unhealthy food intake in unsuccessful restrained eaters. Appetite. 2020;147:104574.

33. Binder A, Naderer B, Matthes J. A "forbidden fruit effect": an eyetracking study on children's visual attention to food marketing. Int J Environ Res Publ Health. 2020;17(6):1859 This is an important study because it clearly shows how individual susceptibility in food marketing research can be investigated and why some groups are more susceptible for food marketing than others. 
34. de Droog SM, Buijzen M, Valkenburg PM. Enhancing children's vegetable consumption using vegetable-promoting picture books. The impact of interactive shared reading and character-product congruence. Appetite. 2014;73:73-80.

35. Folkvord F, de Bruijne M. The effect of the promotion of vegetables by a social influencer on adolescents' subsequent vegetable intake: a pilot study. Int J Environ Res Public Health. 2020;17(7):2243.

36. Folkvord F, Laguna-Camacho A. The effect of a memory-game with images of vegetables on children's vegetable intake: an experimental study. Appetite. 2019;134:120-4.

37. Folkvord F, Roes E, Bevelander K. Promoting healthy foods in the new digital era: an experimental study on the effect of a popular versus fictitious 'insta-influencer' on brand attitude and purchase intentions. Under review.

38. Charry KM. Product placement and the promotion of healthy food to pre-adolescents: when popular TV series make carrots look cool. Int J Advert. 2014;33(3):599-616.

39. Folkvord F, Anastasiadou DT, Anschütz D. Memorizing fruit: the effect of a fruit memory-game on children's fruit intake. Prev Med Rep. 2017;5:106-11 This is an interesting and relevant study because it shows that an easy implementation that is conducted in an entertaining way could increase the intake of fruits among young children.

40. Coates AE, Hardman CA, Halford JC, Christiansen P, Boyland EJ. Social media influencer marketing and children's food intake: a randomized trial. Pediatrics. 2019;143(4).

41. Baldassarre F, Campo R. A character a day keeps the fruit on display: the influence of cartoon characters on preschoolers' preference for healthy food. Int J Mark Bus Syst. 2015;1(3):260-74.

42. Gonçalves S, Ferreira R, Conceição EM, Silva C, Machado PP, Boyland E, et al. The impact of exposure to cartoons promoting healthy eating on children's food preferences and choices. J Nutr Educ Behav. 2018;50(5):451-7.

43. Franken S, Smit CR, Buijzen M. Promoting water consumption on a Caribbean island: an intervention using children's social networks at schools. Int J Environ Res Public Health. 2018;15(4):713.

44. Thaler RH, Sunstein CR. Libertarian paternalism. Am Econ Rev. 2003;93(2):175-9.

Publisher's Note Springer Nature remains neutral with regard to jurisdictional claims in published maps and institutional affiliations. 